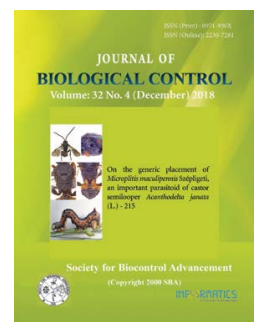

Research Article

\title{
Morphological and molecular characterization of Microplitis maculipennis Szépligeti (Hymenoptera: Braconidae) from India with notes on its generic placement
}

\author{
THIRUVENGADAM VENKATESAN ${ }^{1}{ }^{*}$, ANKITA GUPTA ${ }^{1}$, RAVI P. MORE ${ }^{2}$, PREETHI RAGURAMAN ${ }^{3}$ and REETA \\ BASKHAR $^{1}$ \\ ${ }^{1}$ ICAR-National Bureau of Agricultural Insect Resources, Post Box. No. 2491, H.A. Farm Post, Hebbal, Bangalore - 560024, \\ Karnataka, India \\ ${ }^{2}$ National Centre for Biological Sciences, TIFR, Bangalore - 560065, Karnataka, India \\ ${ }^{3}$ SRM University, Chennai - 603203, Tamil Nadu, India \\ *Corresponding authorE-mail: tvenkat12@gmail.com
}

\begin{abstract}
Microplitis maculipennis Szépligeti is an important parasitoid of castor semilooper Acanthodelta janata (L.) (Lepidoptera), a major pest of castor (Ricinus communis L.). Microplitis Förster shares remarkable morphological resemblance with moderately diverse genus Snellenius Westwood. In this study, molecular characterization of M. maculipennis was done using Cytochrome Oxidase I (COI) to confirm its generic placement in the respective genus. The Bayesian Inference (BI) and Maximum Likelihood (ML) phylogenetic analysis performed with a total of 354 published BOLD database sequences (after pre-processing of a total of 2257 COI sequences) of Microplitis and Snellenius species, representing 129 named species and 226 species determined only to genus raises doubts on the retention of both these genera separately. Our studies reveal that COI gene could not discriminate Microplitis and Snellenius species clearly.
\end{abstract}

KEY WORDS: Acanthodelta janata, barcode, COI, Microplitis maculipennis, Snellenius

(Article chronicle: Received: 07-08-2018; Revised: 19-11-2018; Accepted: 01-12-2018

\section{INTRODUCTION}

Microplitis (Förster, 1862), an apomorphic genus, is known with the type species Microgaster sordipes Nees. Microplitis Szepligeti contains almost 200 species worldwide (Fernández-Triana and Ward, 2017; Fernández-Triana et al., 2015). The genus is diverse and well documented from the Holarctic region in comparison with the Neotropical, tropical and subtropical regions. It is also well known from the Australasian region (Austin and Dangerfield, 1992, 1993). We are exploring monophyly of Microplitis as this genus belongs to one of the group of wasps, the 'microgastroid complex,' which is a monophyletic assemblage of approximately 50,000 species within the family Braconidae that all employ viruses named Bracoviruses (BVs) during parasitism of lepidopteran hosts (Burke, 2016). The species used in our study M. maculipennis Szepligeti exclusively attacks lepidopteran hosts- Acanthodelta janata (L.), Helicoverpa armigera (Hübner), H. zea (Boddie), Dysgonia algira (L.) and Elygea maternal (Linn.) (Austin and Dangerfield, 1993; Gupta, 2013).
Microplitis maculipennis (Fig. 1) is an important parasitoid of castor semilooper Acanthodelta janata (L.) (Lepidoptera: Erebidae) (Fig. 2A) and causes 70-80\% parasitization (Fig. 2B) (Singh et al., 2008). Acanthodelta janata is a major pest of castor (Ricinus communis L.) and also attacks other host plants including Vigna radiata, Bauhinia variegata, Rosa, Punica granatum, Ziziphus mauritiana, Mangifera indica, Citrus, Tridax, Cardiospermum, Ficus, Bauhinia, etc. (Jairamaiah et al., 1975; Somasekhar et al., 1990).

The generic limits between Microplitis and Snellenius based on morphological studies have been controversial since long (Nixon, 1965; Mason, 1981; Austin and Dangerfield, 1992 1993; Fernandez-Triana et al., 2015). The present study was undertaken to confirm the correct generic placement of the species $M$. maculipennis. As the majority of the BOLD sequences for these two genera were based on mitochondrial Cytochrome Oxidase I (COI) gene, the same was chosen for the present study. Recently 

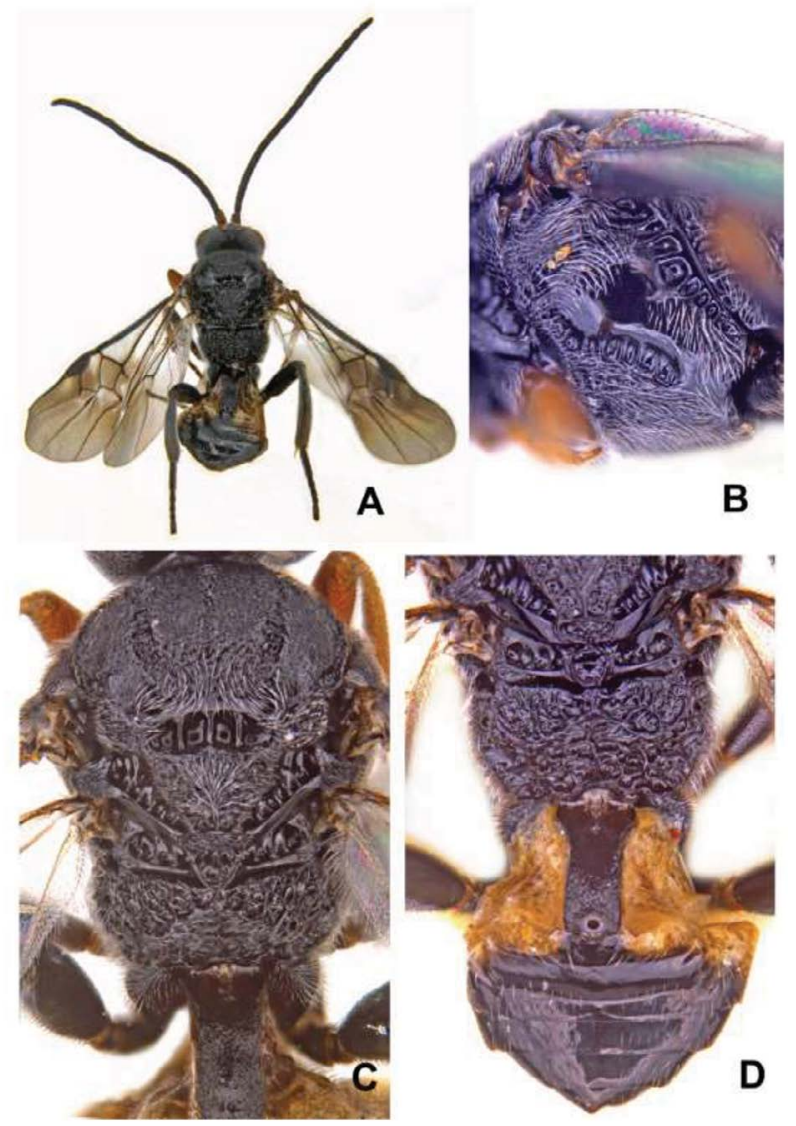

Fig. 1. Microplitis maculipennis Szepligeti: A. Habitus in dorsal view; B. Mesopleuron in lateral view; C. Dorsal view of mesosoma with first tergite in part; D. Dorsal view of metasoma with mesosoma in part.

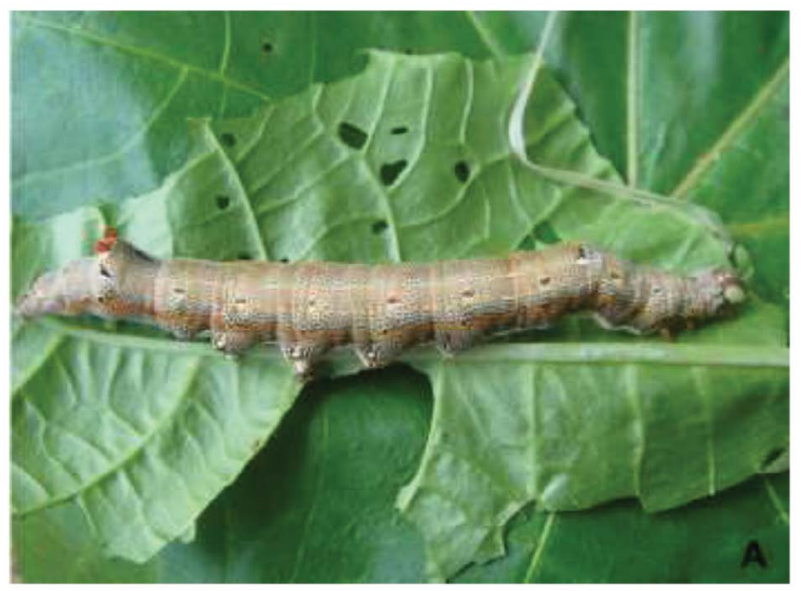

Fig. 2A. Unparasitized caterpillar Acanthodelta janata (Linnaeus).

molecular based identification of insects using mitochondrial Cytochrome Oxidase I gene (COI) is gaining importance due to shortfalls in morphology-based identification (Erlandson et al., 2017; Venkatesan et al., 2016; Gupta et al., 2016).

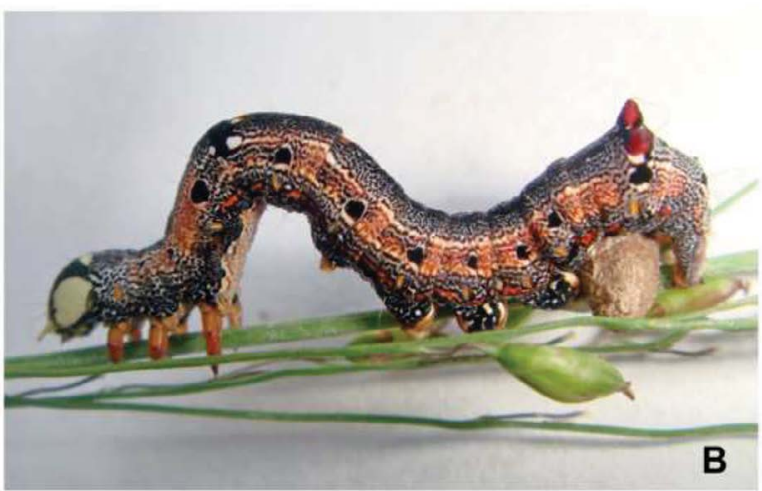

Fig. 2B. Parasitized Acanthodelta janata caterpillar with a cocoon of Microplitis maculipennis.

Cytochrome Oxidase I (COI) of the mitochondrial DNA has been widely used as markers for understanding the evolutionary relationships among different organisms (Õunap and Viidalepp, 2009). Furthermore, COI gene can be considered as universal bioidentification system for animals (Hebert et al., 2003). Mardulyn and Whitefield (1999) used COI marker to study the phylogenetic relationships of hymenopteran parasitoids.

The genus Microplitis can be recognized by a large areolet, mesopleuron without prepectal carina, roughly sculptured propodeum often with a median longitudinal carina, propodeum evenly curved in the lateral view, shape and sculpture of first metasomal tergite, and with a weakly defined groove separating second and third tergum (Nixon, 1965; Mason, 1981; Austin and Dangerfield, 1992; 1993). Genus Snellenius Westwood was redescribed by Mason (1981). The species under Snellenius are characterized by highly exaggerated propodeum that comprises of two faces meeting transversely at a sharp angle of distinctly less than $90^{\circ}$; deep and strongly crenulate notauli; middle lobe of the mesoscutum raised above the level of lateral lobes and antenna with flagellar segments strongly compressed. Nixon (1965) mentioned that sharp line of division between the two genera is missing. Microplitis shares remarkable resemblance with closely allied genus Snellenius except for more sculptured notauli, coarsely reticulate propodeum with strong angulation and distinct prepectalcarina in the later (Nixon, 1965; Mason, 1981; Austin and Dangerfield, 1992). Many species are intermediate between Snellenius and Microplitis (especially in south-east Asia). Mason (1981) diagnosed Snellenius species to be with a partial or complete, usually irregular, prepectal carina. In Indo-Australian fauna this character appears to adequately separate these genera (Austin and Dangerfield, 1992). Fernández-Triana et al., (2015) added that Snellenius can be separated by strongly excavated and sculptured notauli and scutellar disc, very wide and deep scutoscutellar sulcus, 
and propodeum divided into two distinct faces clearly marked by a strong angulation (in the lateral view) and a transverse carina (in the dorsal view).

Coming to $M$. maculipennis, the species chosen in the present study, Gupta (2013) provided its detailed description (Fig. 1). Female body length 3.36-4.0 mm. Body black; scape and pedicel brown, flagellomeres dark brown to black; ocelli yellow brown, fore legs yellowbrown (more so on apical half of femur and tibia), mid legs dark brown (except yellowish brown apical tip of femur and basal tip of tibia), hind legs black; laterotergites of T1-T3 and first three sternites light yellow brown to off white; T1 median tergite black; median triangular field in T2, T4-T7 black; wings infuscate brown in apical $2 / 3^{\text {rd }}$, fore wing slightly darker than hind wing, with darker areas below stigma and through marginal cell, venation dark brown, stigma uniformly dark brown.

Head, densely pilose; eyes densely pilose; antennae as long as body or a little shorter in few specimens. Mesoscutum with medial lobe rugose punctuate and higher than lateral lobes; lateral lobes less rugose than median lode, with faint punctuations; notauli strongly indicated, meeting posteriorly into reticulate-punctate area, medial furrow impressed, crenulate-punctate; medial lobe slightly raised along longitudinal line; scutoscutellar sulcus very broad, deep, divided by wide costulae; dorsal scutellum very coarsely rugulose-punctate and pilose; propodeum with two faces that meet sharply at about $90^{\circ}$, very coarsely rugose-punctate; medial longitudinal carina not clear; mesopleuron with epicnemial area strongly raised, carinate, pilose, epicnemial furrow broad, coarsely crenulate; metapleuron coarsely reticulate-rugose and pilose. Fore wings infuscate in apical half, basal $1 / 3^{\text {rd }}$ hyaline; pterostigma dark brown; 1-M very slightly curved; areolet of moderate size. Metasoma with T1 2.4-3.0 $\times$ as long as its apical width, slightly rugose except for shining apical patch, widest at extreme base, parallel sided, and widening very slightly in apical half; T2 smooth, pilose along posterior margin, triangular in shape, with median field indicated by median area; T2 as long as T3 medially, suture between T2 and T3 moderately distinct; T3-T7 with transverse rows of hairs, mostly in posterior $2 / 3^{\text {rd }}$, smooth and shining.

The members of this genus are koinobiont larval endoparasitoids of Lepidoptera more precisely, the noctuid genera Helicoverpa and Spodoptera. The majority of the hosts belong to the families Noctuidae, Erebidae, and to some extent Sphingidae and Lymantriidae (presently in Erebidae as Lymantriinae). Worldwide a huge anomaly regarding host association of Microplitis and Snellenius has been observed. In India, the majority of the Microplitis hosts are from families Noctuidae and Erebidae and exhibit solitary parasitism (Gupta, 2013; Ranjith et al., 2015). Austin and Dangerfield (1993) recorded that Microplitis parasitizes the members of Noctuidae, Notodontidae and Erebidae, and the Oriental Snellenius parasitizes Noctuidae and Sphingidae. However, contradictory to the above host records, FernándezTrianaet et al., (2015) found that in ACG inventory of Costa Rica, Microplitis exclusively parasitizes sphingids, while Snellenius parasitizes members of Noctuidae and Erebidae.

In this study, $M$. maculipennis was identified morphologically and with molecular marker COI gene. Further, we analyzed the phylogeny of Microplitis and Snellenius by using the COI available in public database to ascertain whether species belonging to Microplitis and Snellenius form distinct clades or not.

\section{MATERIALS AND METHODS}

This paper is based on study of Microplitis maculipennis specimens reared from six different locations in southern India (housed at the ICAR-National Bureau of Agricultural Insect Resources (NBAIR), Bangalore, India).

A roving survey was conducted in six locations viz., Attur, Malliyakkarai, Namagiripettai, Vazhapadi, Yethapur, and Thumbal of Tamil Nadu in southern India from October 2014 to December 2014 fortnightly (Table 1). Nearly 500 larvae of Acanthodelta janata were hand-collected from each location and observed for parasitization by $M$. maculipennis at room temperature and stored in vials for further studies at ICAR-National Bureau of Agricultural Insect Resources (ICAR-NBAIR). Parasitized larvae and adult wasps were characterized using COI. Also $A$. janata was also characterized using the above-mentioned marker for the host confirmation.

\section{DNA Extraction and COI Amplification}

Field collected $A$. janata were further reared on castor leaves in the laboratory and observed for parasitization. Larvae of $A$. janata, freshly formed cocoons and adults of M. maculipennis were stored in $-20^{\circ} \mathrm{C}$ until further study. An individual sample of cocoon and adult of $M$. maculipennis and $A$. janata larvae were placed in $1.5 \mathrm{ml}$ micro centrifuge tubes separately. Genomic DNA was isolated by using DNA extraction kit (QIAGEN DN easy blood and tissue kit Cat. 69504, Germany).

COI gene was amplified by PCR with the volume of $30 \mu \mathrm{l}$ reaction. It contained $2 \mu \mathrm{l}$ DNA template, $3 \mu \mathrm{l}$ PCR buffer, $1 \mu \mathrm{l}$ dNTPs $1.5 \mu \mathrm{l}$ forward LCO 14905'-GGTCAACAAA TCATAAAGATATTGG3' and reverse primers HCO 2198 
Table 1: Per cent parasitism of Microplitis maculipennis on Acanthodelta janata

\begin{tabular}{|c|c|c|c|c|c|c|}
\hline \multirow[t]{2}{*}{ Location } & \multicolumn{2}{|c|}{ GPS } & \multicolumn{4}{|c|}{ Parasitism (\%) } \\
\hline & $\begin{array}{l}\text { Longitude \& } \\
\text { Latitude }\end{array}$ & Elevation & $\begin{array}{c}\text { Oct. } 2014 \\
\text { (A month crop) }\end{array}$ & $\begin{array}{c}\text { Nov. } 2014 \\
\text { (2 months crop) }\end{array}$ & $\begin{array}{c}\text { Dec.2014 } \\
\text { (3 months crop) }\end{array}$ & Average \\
\hline Attur & $\begin{array}{l}11.59629^{\circ} \mathrm{N} \\
78.59892^{\circ} \mathrm{E}\end{array}$ & $225.0 \mathrm{~m}$ & 40 & 65 & 63 & 56 \\
\hline Malliyakkarai & $\begin{array}{l}11.56893^{\circ} \mathrm{N} \\
78.49935^{\circ} \mathrm{E}\end{array}$ & $274.5 \mathrm{~m}$ & 73 & 72 & 69 & 71 \\
\hline Namagiripettai & $\begin{array}{l}11.46064^{\circ} \mathrm{N} \\
78.27415^{\circ} \mathrm{E}\end{array}$ & $259.8 \mathrm{~m}$ & 63 & 69 & 75 & 69 \\
\hline Vazhapadi & $\begin{array}{l}11.65548^{\circ} \mathrm{N} \\
78.40126^{\circ} \mathrm{E}\end{array}$ & $311.9 \mathrm{~m}$ & 62 & 60 & 60 & 61 \\
\hline Yethapur & $\begin{array}{l}11.66314^{\circ} \mathrm{N} \\
78.47662^{\circ} \mathrm{E}\end{array}$ & $277.3 \mathrm{~m}$ & 88 & 89 & 81 & 86 \\
\hline Thumbal & $\begin{array}{l}11.77970^{\circ} \mathrm{N} \\
78.51923^{\circ} \mathrm{E}\end{array}$ & $393.4 \mathrm{~m}$ & 67 & 60 & 79 & 67 \\
\hline
\end{tabular}

5'-TAAACTTCAGGGTGACCAAAAAATCA-3') (Folmer et al., 1994), $1 \mu$ l Taq Polymerase and $20 \mu$ of sterile distilled water. The cycling conditions for COI (initial denaturation at $95^{\circ} \mathrm{C}$ for 4 min followed by 34 cycles each of denaturation at $94^{\circ} \mathrm{C}$ for $30 \mathrm{sec}$, annealing at $50^{\circ} \mathrm{C}$ for $1.20 \mathrm{~min}$ and extension at $72^{\circ} \mathrm{C}$ for $2 \mathrm{~min}$ followed by a final extension step at $72^{\circ} \mathrm{C}$ for $7 \mathrm{~min}$. The size of PCR product was determined with $1.2 \%$ agarose with a standard size. Then the PCR products were sent to automatic sequencing (Eurofins Genomics India Pvt. Ltd., Bangalore).

Sequence chromatograms of forward and reverse sequences were analyzed and trimmed for stop codons/nuclear copies in order to know the frame shift (https://www.ncbi.nlm. nih.gov/orffinder/). Further, the sequences were assembled using CLC Genomics Workbench 7. The similarity search of resulting consensus sequences was performed using Basic Local Alignment Search Tool (BLAST) against sequences in GenBank database to confirm that the sequence was indeed corresponding taxonomy. All COI generated consensus sequences have been deposited in NCBI GenBank database The accession numbers of $A$. janata and M. maculipennis are given in Table 3 and Table 4, respectively.

\section{Sequence retrieval from BOLD database}

In order to compare our isolated sequences with available database sequences, we referred to BOLD (http:// v4.boldsystems.org/) to download COI sequences of Microplitis and Snellenius. The initial data set was comprised of 2257 COI sequences, but we pre-processed the data before further analysis. We removed poor quality sequences from the dataset which were having - symbol and $\mathrm{N}$ starches ( $>=5 \mathrm{bp}$ ). The filtered dataset comprised of 1425 sequences which had $>600$ bp length. Then, we included only one representative sequence per Microplitis or Snellenius species. Thus, we ended retaining 354 sequences, representing 129 named species and 226 species determined only to genus level. Also, we included 12 COI sequences of M. maculipennis populations from our study, and one sequence of Diolcogaster sp. (KM996615) was included as an outgroup. After pre-processing, the final dataset consisted of $367 \mathrm{COI}$ sequences.

\section{Phylogenetic analysis}

Since, there are no other sequences available in any public database for this species, all analyses were carried out using COI gene nucleotide sequences. All the sequences were aligned using the program MUSCLE with the default alignment parameters (Edgar, 2004). To refine and correct the alignment, we used trim AI software to concatenate trimmed alignment with the automated 1 option before substitution model prediction (Capella-Gutiérrez et al., 2009). Phylogenetic relationships were estimated by Bayesian-Inference (BI), with support (clade posterior probabilities values) showed on the respective tree. Best-fit substitution models were selected by the Akaike information criterion as implemented in PartitionFinder version 1.1.1 software (Lanfear et al., 2012). Bayesian-Inference analysis was performed in MrBAYES v3.1.2 (Ronquist et al., 2012), using the (MC) 3 algorithm, with three heated and one cold simultaneous Markov chains per run and two independent runs per analysis as executed by default. The stop-rule was set and we increased the number of generations until the average deviation of split frequencies reached a value below 0.01 . Markov Chain Monte Carlo (MCMC) started from a random tree, sampling one of every 500 generations. The analyses consisted of 14,830,000 MCMC generation, with the first $7415(25 \%)$ of the trees discarded as burn-in out of 29,660 trees. The remaining trees were used to build a majority-rule 
consensus tree on which the Posterior Probabilities (PP) was shown. The resulting nexus formatted BI phylogenetic tree was imported, edited and visualised in the Fig Tree software version 1.4.2 (http://tree.bio.ed.ac.uk/software/figtree/). In addition to Baysian tree, we generated Maximum Likelihood tree using RAxML (v7.0.4) tool with parameters 'ML+ Rapid Bootstrap' and kept 1000 searches bootstrap support values for each node (Stamatakis, 2006) (Fig. 4). Tree file edited in the FigTree software.

\section{RESULTS AND DISCUSSION}

\section{Sequence and phylogenetic analysis}

We obtained a total of 354 published BOLD database sequences (after pre-processing of a total of $2257 \mathrm{COI}$ sequences) of Microplitis or Snellenius species, representing 129 named species and 226 species determined only to

Table 2. Summary statistics for COI loci from Microplitis species

\begin{tabular}{|l|l|}
\hline Characteristics & COI \\
\hline No. of sequences analyzed & 12 \\
\hline Total no. of sites & 675 \\
\hline Conserved sites & 452 \\
\hline Variable sites & 221 \\
\hline Parsimony informative sites & 150 \\
\hline
\end{tabular}

genus. This dataset was in the range of 600 to $658 \mathrm{bp}$ in length. Twelve populations of $M$. maculipennis reared from southern India were sequenced from mt DNA COI with 614 to $624 \mathrm{bp}$. The data were aligned using MUSCLE (Thompson et al., 1994). The alignment of the COI dataset resulted in a total of 675 nucleotide sites, of which 221 (47.78\%) were variable sites and $150(40.82 \%)$ were parsimony-informative (Table 2). For the Bayesian inference analysis, the model was applied to the subset partitions positions 1, 2, and 3. For all the three positions, the General Time Reversible (GTR) with gamma distribution (G)+Invariant (I) substitution model was predicted with best-fit partitioning schemes (lnL: -16713.73231 and AIC: 34953.46462) using Partition Finder version 1.1.1 and further it was used to generate a phylogenetic tree.

The Bayesian Inference (BI) and Maximum Likelihood (ML) phylogenetic trees of the Microplitis sp. and Snellenius sp. is shown in Fig. 3 and Fig. 4, respectively. The clades Posterior Probability (PP) values are colored based on the auto-scale range between minimum and maximum values in Fig. 3. In case of ML tree (Fig. 4), Bootstrap Values (BV) is given at each node. In $\mathrm{BI}$ tree, we have obtained two distinct clades, $\mathrm{A}(\mathrm{PP}=0.99)$ as a single separate cluster, while $\mathrm{B}$ clade $(\mathrm{PP}=0.88)$ is further divided into 11 major subclades $\mathrm{B}_{1}-\mathrm{B}_{11}$. On similar line, we have obtained two major Clade $\mathrm{A}$ and $\mathrm{B}$ in ML tree, Clade contains seven sequences of Snellenius

Table 3. Characterization of Acanthodelta janata using CO1

\begin{tabular}{|l|l|l|l|c|}
\hline S1.No. & Location & Stage & Strain & GenBank Acc. No. (COI) \\
\hline 1. & Attur & A. janata larva & AJ-1-AT & KP765518 \\
\hline 3 & Vazhapadi & A. janata larva & AJ-4-VA & KP765521 \\
\hline 5 & Thumbal & A. janata larva & AJ-5-TH & KP765522 \\
\hline 7 & NamagiriPettai & A. janata larva & AJ-7-NA & KP765524 \\
\hline
\end{tabular}

Table 4. Characterization of Microplitis maculipennis using COI gene

\begin{tabular}{|l|l|l|l|c|}
\hline Sl.No. & Location & Stage & Strain & GenBank Acc. No. \\
\hline 1 & Malliyakari & Cocoon & MM-8-MA & KP759295 \\
\hline 2 & Malliyakari & Adult & MM-1-MA & KP759288 \\
\hline 3 & NamagiriPettai & Cocoon & MM-11-NA & KP759298 \\
\hline 4 & NamagiriPettai & Adult & MM-2-NA & KP759289 \\
\hline 5 & Attur & Cocoon & MM-7-AT & KP759294 \\
\hline 6 & Attur & Adult & MM-6-AT & KP759293 \\
\hline 7 & Thumbal & Cocoon & MM-10-TH & KP759297 \\
\hline 8 & Thumbal & Adult & MM-4-TH & KP759291 \\
\hline 9. & Vazhapadi & Adult & MM-5-VA & KP759292 \\
\hline 10. & Vazhapadi & Cocoon & MM-9-VA & KP759296 \\
\hline 11. & Yethapur & Adult & MM-3-YE & KP759290 \\
\hline
\end{tabular}




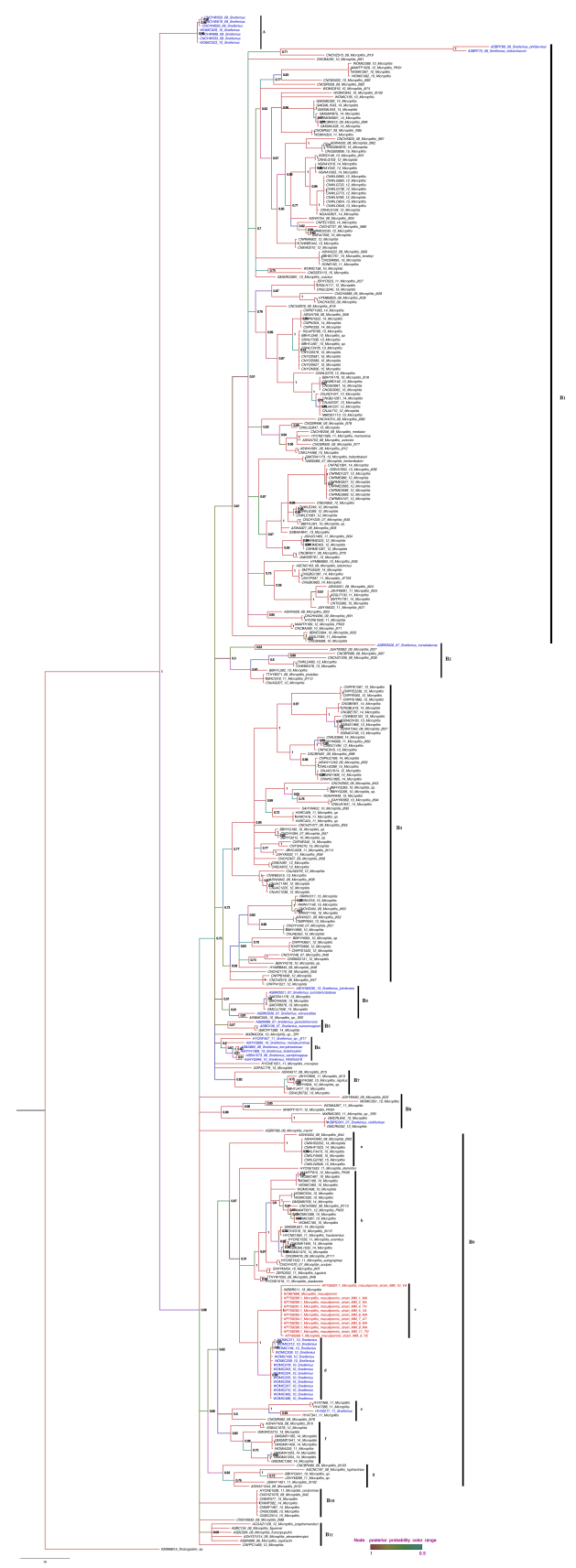

Fig. 3. The Bayesian inference phylogenetic tree of the Microplitis sp. and Snellenius sp.

species with confidence $\mathrm{BV}=99$. Further, $\mathrm{B}_{1}(\mathrm{PP}=0.61)$ is split into many subclades in BI tree, we found that the majority of the species belongs to Microplitis in this clade except for two sequences of Snellenius phildevriesi and $S$. isidrochaconi. These two species form a separate clade with Microplitis jft81 with $\mathrm{PP}=0.71$. In ML tree, same species sequence are grouped in clade B2C10. Similar scenario is observed in subclade B2, Snellenius irenebakerae which is clustered with other species of Microplitis $(\mathrm{PP}=0.63)$ and the rest of sequences are dominated with Microplitis species. In ML tree, same species sequence are grouped in clade B2C6 with $\mathrm{BV}=59$. In $\mathrm{BI}$ tree, species belonging to Microplitis formed several strongly supported an independent subclades, $\mathrm{B} 3(\mathrm{PP}=0.73), \mathrm{B} 7(0.82), \mathrm{B} 10(\mathrm{PP}=1)$ and $\mathrm{B} 11(0.58)$ the latter with lower support. In ML tree, we observed same clades species in $\mathrm{B} 2 \mathrm{C} 8(\mathrm{BV}=91), \mathrm{B} 2 \mathrm{C} 7(\mathrm{BV}=99)$, and $\mathrm{B} 2 \mathrm{C} 1$ $(\mathrm{BV}=100)$.

Few members of Snellenius ( $S$. johnkresssi, S. lucindamcdadeae, S. velvaruddae, S. gerardoherreai, S. warrenwageri, S. mariakuzminae, S. kerrydressleare, S. bobdressleri, S. sandyknappae, and Snellinus Whitfield 19) formed clades B4, B5, and B6 but with low support (PP 0.5-0.57). In case of ML tree, same species are grouped in subclade $\mathrm{B} 2 \mathrm{C} 9$. In subclade $\mathrm{B} 8(\mathrm{PP}=0.98)$ in $\mathrm{BI}$ tree and $\mathrm{B} 1 \mathrm{C} 2(\mathrm{BV}=100)$ in ML tree, S. vickifunkae species showed close relationship with Microplits sp. sff3 and other members with high support $(\mathrm{PP}=1)$. $\mathrm{B} 9(\mathrm{PP}=0.66)$ clade in $\mathrm{BI}$ tree and B2C4 clade in ML tree was split into 7 subclades: a-g. Our study sequences of $M$. maculipennis are closely allied to Snellenius species with high support value ( $\mathrm{PP}=1 ; \mathrm{BV}=98)$, while Clade $a(\mathrm{PP}=1), \mathrm{b}(\mathrm{PP}=1), \mathrm{f}(\mathrm{PP}=0.85), \mathrm{g}(\mathrm{PP}=0.93)$ consists exclusively of Microplitis members. In clade e $(\mathrm{PP}=1)$, only one Snelleniusis embedded within Microplitis species. In case of Maximum likelihood phylogenetic tree, The COI gene tree displayed a very close topology with BI tree and both methods gave similar branching, which slightly differed at the internal nodes (Fig. 4).

Microplitis maculipennis is an important parasitoid of castor semilooper $A$. janata and this was much evident from our field collected populations. This species is distributed in Australia, India (widespread), Malaysia, Papua New Guinea and Thailand. Austin and Dangerfield (1993) stated that Microplitis shares remarkable resemblance with Snellenius except for more impressed and sculptured notauli and propodeum, and distinct prepectalcarina in the later. Since many of the Indian specimens of M. maculipennis do not posses distinct prepectal carina, hence the species was placed in the genus Microplitis (Gupta, 2013).

In this study, an effort was made to recognize and discriminate Microplitis species and understand their evolutionary relationships based on COI gene, through publically available COI sequences and phylogentic analysis. The clear-cut generic limits between Microplitis and Snellenius and the generic placement of M. maculipennis based on morphological studies have always been controversial. Our studies show that all the new sequences of M. maculipennis have close similarity with the Snellenius species from the Oriental region. This is in congruence with the fact that the intergeneric delimitation of Microplitis and Snellenius is more difficult in the Oriental region. 


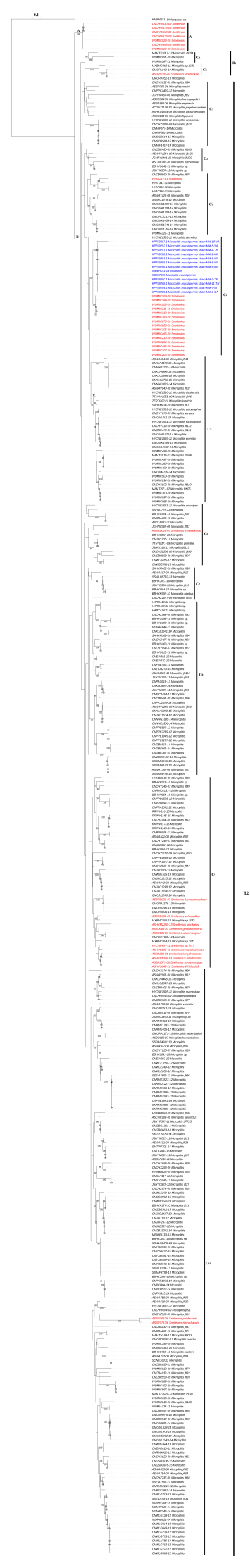

Fig. 4. The Maximum Likelihood Phylogenetic tree of the Microplitis sp. and Snellenius sp.
In our previous molecular-based studies, it was confirmed that the DNA barcoding of trichogrammatids (Hymenoptera: Trichogrammatidae) by using the mitochondrial cytochrome oxidase-I marker sequences was a practical approach for shaping molecular diversity (Venketesan et al., 2016). In addition to that, the phylogenic analysis was performed to identify and classify various species-groups of the genus Glyptapanteles Ashmead, 1904 (Insecta: Hymenoptera: Braconidae: Microgastrinae) (Gupta et al., 2016).

\section{CONCLUSION}

The present analysis suggests that these two genera demands comprehensive study of the world fauna as it raises doubts about the identity of many of the sequences which exist in the Gen Bank for which many of the voucher specimens need to be re-examined in order to confirm which species should strictly fall into Microplitis or otherwise, if they are two discrete genera. There is also a strong possibility that Microplitis and Snellenius might not retain their separate generic status in future based on combined morphological and molecular analysis and considering the huge anomaly in their respective host associations. Furthermore, multigene phylogeny is required to differentiate the species under both genera substantially.

\section{ACKNOWLEDGEMENTS}

We thank the Indian Council of Agricultural Research (ICAR) and Dr. C. R. Ballal (Director, ICAR-NBAIR) for research encouragement and for providing necessary facilities. AG is extremely grateful to Dr José L. FernándezTriana, Canadian National Collection of Insects (CNC) Ottawa, Canada for valuable comments and suggestions to improve this manuscript.

\section{REFERENCES}

Austin AD, Dangerfield PC. 1992. Synopsis of Australasian Microgastrinae (Hymenoptera: Braconidae), with a key to genera and description of new taxa. Invertebr Taxon. 6: 1-76. doi: 10.1071/ IT9920001

Austin AD, Dangerfield PC. 1993. Systematics of Australian and New Guinean Microplitis Foerster and Snellenius Westwood (Hymenoptera: Braconidae: Microgastrinae), with a review of their biology and host relationships. Invertebr Taxon. 7: 1097-1166. https://doi.org/10.1071/ IT9931097

Burke GR. 2016. Analysis of Genetic Variation across the Encapsidated Genome of Microplitis demolitor Bracovirus in Parasitoid Wasps. PLoS One 11(7): e0158846. https:// doi.org/10.1371/journal.pone.0158846. 
Capella-Gutierrez S, Silla-Martínez JM, Gabaldón T. 2009. trimAl: a tool for automated alignment trimming in large-scale phylogenetic analyses. Bioinformatics 25: 1972-1973. https://doi.org/10.1093/bioinformatics/ btp348 PMid:19505945 PMCid:PMC2712344

Edgar RC. 2004. MUSCLE: multiple sequence alignment with high accuracy and high throughput. Nucleic Acid Res. 19: 1792-1797. https://doi.org/10.1093/nar/ gkh340 PMid:15034147 PMCid:PMC390337

Erlandson MA, Holowachuk J, Sieminsa EA, Hummel J, Otani J, Floate KD. 2017. Development of a multiplex polymerase chain reaction assay for the identification of common cutworm species (Lepidoptera: Noctuidae) infesting canola in western Canada. Can Entomol. 149: 540-548. https://doi.org/10.4039/tce.2017.5

Fernández-Triana J, Ward D. 2015. Microgastrine Wasps of the World. Available from: http://www.microgastrinae. myspecies.infoicrogastrinae

Fernández-Triana JL, Whitfield JB, Smith MA, Kula RR, Hallwachs W, Janzen DH. 2015. Revision of the genera Microplitis and Snellenius (Hymenoptera, Braconidae, Microgastrinae) from Area de Conservacion Guanacaste, Costa Rica, with a key to all species previously described from Mesoamerica. Deut Entomol Z. 62: 137-201. https://doi.org/10.3897/dez.62.5276. https:// doi.org/10.3897/dez.62.5276

Folmer, O., Black, M., Hoeh, W., Lutz, R. \& Vrijenhoek, R. 1994. DNA primers for amplification of mitochondrial cytochrome c oxidase subunit I from diverse metazoan invertebrates. Mol Mar Biol Biotechnol. 5: 294-299 PMid:7881515

Förster A. 1862. Synopsis der Familien und Gattungen der Braconen. Verhandlungen des Naturhistorischen Vereins der preussischen Rheinlande und Westfalens. 19: $225-88$.

Gupta A. 2013. Revision of the Indian Microplitis Foerster (Hymenoptera: Braconidae: Microgastrinae), with description of one new species. Zootaxa 3620: 429-452. http://dx.doi.org/10.11646/zootaxa.3620.3.5 https://doi. org/10.11646/zootaxa.3620.3.5

Gupta A, Venkatesan T, More RP. 2016. Morphological and Molecular Characterization of Reared Parasitoid Wasps of the Genus Glyptapanteles Ashmead 1904 (Insecta: Hymenoptera: Braconidae: Microgastrinae) Associated with Lepidoptera in India. PLoS One 11: e0150765. https://doi.org/10.1371/journal.pone.0150765 PMid:26942740 PMCid:PMC4778878

Hebert PDN, Cywinska A, Ball SL, Dewaard JR. 2003. Biological identifications through DNA barcodes. Proc $R$ Soc Lond (Biol). 270: 313-322. https://doi. org/10.1098/rspb.2002.2218

Jairamaiah M, Gubbaiah DMF, Thontadarya TS. 1975. New host record of castor semilooper, Achaea janata. Curr Sci. 44: 248-249.

Lanfear R, Calcott B, Ho SY, Guindon S. 2012. PartitionFinder: Combined Selection of Partitioning Schemes and Substitution Models for Phylogenetic Analyses. Mol Biol Evol. 29: 1695-1701. https://doi. org/10.1093/molbev/mss020 PMid:22319168

Mason WRM. 1981. The polyphyletic nature of Apanteles Foerster (Hymenoptera: Braconidae): A phylogeny and reclassification of Microgastrinae. Mem Entomol Soc Can. 1-147. https://doi.org/10.4039/entm113115fv

Mardulyn P, Whitefield B. 1999. Phylogenetic signal in the COI, $16 \mathrm{~S}$ and $28 \mathrm{~S}$ genes for inferring relationships among genera of Microgastrinae (Hymenoptera: Braconidae): evidence of a high diversification rate in this group of parasitoids. Mol Biol Evol. 12: 282-294.

Nixon G. 1965. A reclassification of the tribe Microgasterini (Hyme $\neg$ noptera: Braconidae). Bull Br Mus Nat Hist Zool. (Natural His $\neg$ tory), Entomology series. Suppl 2: $1-284$.

ÕunapE,ViidaleppJ.2009.DescriptionofCrypsiphonatasmanica sp. nov. (Lepidoptera: Geometridae: Geometrinae), with notes on limitations in using DNA barcodes for delimiting species. Aust $J$ Entomol. 48: 113-124. https://doi. org/10.1111/j.1440-6055.2009.00695.x

Ranjith AP, Rajesh KM, Nasser M. 2015. Taxonomic studies on Oriental Microplitis Foerster (Hymenoptera: Braconidae, Microgastrinae) with description of two new species from South India. Zootaxa 3963: 369-415. https://doi. org/10.11646/zootaxa.3963.3.4 PMid:26249405

Singh S, Singh SK, Sudhakar R. 2008. Validation of Integrated pest management module for castor and pigonpea intercropping system for rainfed agroecosystem. Pest Res J. 20: 217-220.

Somasekhar S, Patil BV, Patil SA. 1990. Occurrence of castor semilooper Achaea janata Linnaeus and its parasitoid Microplitis maculipennis Szepligeti in Raichur. Karnataka J Agric Sci. 6: 200-202. 
Ronquist F, Teslenko M, van der Mark P, Ayres DL, Darling A, Höhna S, Larget B, Liu L, Suchard MA, Huelsenbeck JP. 2012. MrBayes 3.2: efficient Bayesian phylogenetic inference and model choice across a large model space. Syst Biol. 61: 539-542. https://doi.org/10.1093/sysbio/ sys029 PMid:22357727 PMCid:PMC3329765

Stamatakis A. 2006. RAxML-VI-HPC: maximum likelihoodbased phylogenetic analyses with thousands of taxa and mixed models. Bioinformatics 22: 2688-2690. pmid:16928733

Thompson JD, Higgins DG, Gibson TJ. 1994. CLUSTAL W: improving the sensitivity of progressive multiple sequence alignment through sequence weighting, position-specific gap penalties and weight matrix choice. Nucleic Acids Res. 22: 4673-4680. https://doi.org/10.1093/nar/22.22.4673 PMid:7984417 PMCid:PMC308517

Venkatesan T, More RP, Baskar R, Jalali SK, Lalitha Y, Ballal CR. 2016. Differentiation of some indigenous and exotic trichogrammatids (Hymenoptera: Trichogrammatidae) from India based on Internal transcribed spacer- 2 and cytochrome oxidase-I markers and their phylogenetic relationship. Biol Control 101:130-137. https://doi. org/10.1016/j.biocontrol.2016.07.005 